IBT Journal of Business Studies

Volume 14(2), 132-147, 2018

\title{
Systematic Approach of Customer Relationship Management in Much Different Organization
}

\author{
Farooque Ahmed Memon ${ }^{l}$ \\ Soobia Saeed ${ }^{2}$ \\ Asadullah Shaikh \\ Muhammad Ali Memon
}

\begin{abstract}
The aggregate number of target clients does not expand by much rate every year. The entire thought of Customer Relationship Management (CRM) is to oversee and protect the client base of any association. It requires far less exertion and assets to hold client contrasted with drawing in new ones. Offering basic administrations and motivations can prompt client dedication which itself will pull in new clients. Throughout the last few decades' associations have understood the significance of CRM and have attempted diverse approaches to actualize CRM. Those associations that were effective in actualizing CRM were the individuals who comprehended its essential outline. The goal of this venture is to setup rules and skeleton for effectively actualizing CRM in an association, this report will reveal insight in subtle element on different parts of CRM and how an association can hold their current client and also draw in new ones.
\end{abstract}

Keywords: Customer Relationship Management, associations, significance

1- ILMAUniversity formerly-IBT, farooquememon@gmail.com

2- ILMA University formerly-IBT, Soobia_saeed123@hotmail.com

3- Institute of Business and Technology, Karachi, Pakistan, shaikhasad@hotmail.com

4- University of Sindh, Pakistan, Muhammad.ali@usindh.edu.pk 


\section{INTRODUCTION}

CRM (Customer Relationship Management) is a systematic approach which is used to manage company's interaction with its customer/client by using different technologies to organize, automate and synchronize company's sales, marketing, customer support, H.R development, Production, Performance Management, Analysis. It merges all these activities at one platform in order to provide quick support to their customers as well as also for the company's development. The "Data Framework and Management of CRM" good to go establishment or in another industry creates the inquiry what esteem does a client hold to an association? Also what strategies organizations can use to clutch these clients so as to attain relentless benefits?

This report covers the ideas and perspectives of individuals directing research and is fundamentally focused around actualizing rules or skeleton of CRM in any association. The goal of this report is to focus best practice in CRM inside business, heading on to how to execute E-CRM in vast associations. This report will additionally demonstrate the accessible programming for CRM and an assessment of the best practice guide from industry experts i.e. how much consistent it is when connected to mechanical application.

\section{LITERATURE REVIEW}

\section{Introduction}

In succession of past section which characterizes the hypothetical ideas and presentation about Customer Relationship Management. The destination of this part is to present the per user with relevant writing in the field of CRM, additionally give hypothetical examinations which are concerned with the authoritative targets and about how at present these associations are keeping up CRM frameworks.

\section{Objectives of CRM in E-Business}

Distinctive Researchers have characterized diverse targets focused around their points of view, which gives a bland perspective of client relationship administration framework however focused around the parts of business methods. One of the specialist Kim et al created CRM destinations into the accompanying ways.

\section{Customer Knowledge}

As per Kim et al gathering information, inspecting client information, customer maintenance and client securing are the principle parts of the client learning. This could be finished by utilizing information warehousing and information mining strategies. An association utilizes their site as a CRM device to assemble the data identified with clients, for example, online visit for every day, visits for every day and web log information.

\section{Customer Interaction}

According to Kim et al there are number of communication channels to interact with customers effectively. Kim et al emphasizes on a manager's role to monitor the business process to manage communication channels effectively. There are four components of customer interaction (Kim et al cited Stone et al 1996)

- Contacts with company staff-front line and other

- Outbound contact management—mail, telephone, sales visits, and deliveries 
- Physical service environment

- Transaction - price, value, and terms

Kim et al stated that to analyze customer interactions, there are some measures which have to be considered such as number of marketing campaigns, total cost of promotion, frequency of contents, update payments, response channels and so on.

\section{Implementation aspects of CRM}

This exploration is attempting to conceptualize the streams of data framework that leads us into the usage of CRM (Figure 2.1), as such is characterizing the skeleton of execution of CRM. These streams introduce their oblige building difficulties of revelation, investigation, documentation, plan, alongside upkeep, before they could be tied into a CRM venture. To begin with, the deals and showcasing and the unmistakable innovation and methods utilized will be examined, as opposed to impalpable client driven center talked about to a sickening degree in the writing. Second, the back-end operation necessities prompting endeavor asset arranging (ERP) and its coordination with CRM, a territory deficiently tended to in the writing. It is not difficult to secure a connection between the relatives of the back-end to ERP, which is failing to offer the discourses and exploration of the connection in the middle of ERP and CRM. Yet on a very basic level 'CRM/ERP usage are not atypical and to be sure any organization that has made an expansive financing in ERP ought to nearly connect CRM exercises to that speculation' (Chang, 2002). Thirdly, there is the information taking care of innovation, Data warehousing, information mining CRM can't exist without the information taking care of advances of information warehousing, information mining and learning administration Figure Shown Below.

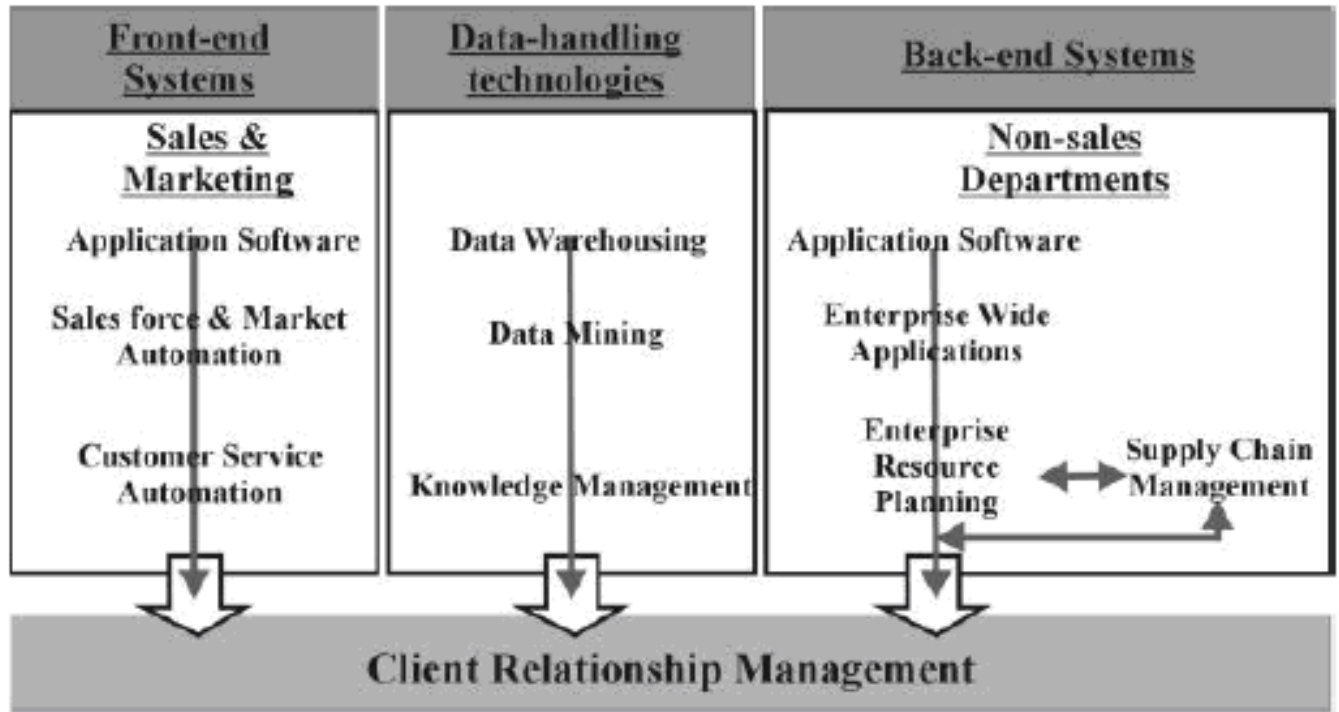

Figure .1: Client Relationship Management

\section{Evaluation of CRM}

In this section of a chapter the tools used to determine the efficiency of CRM by an organization will be discussed. These tools can be used to assess tangible and intangible elements 


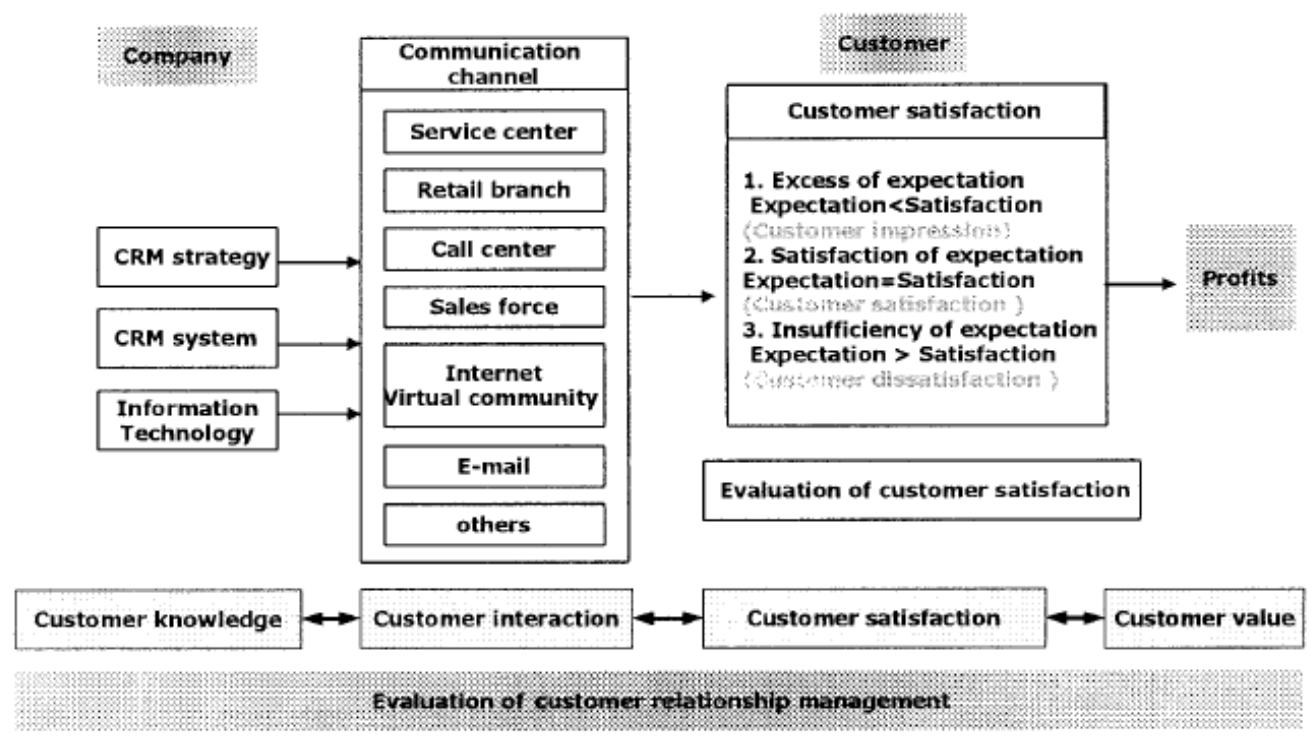

Figure.2: Evaluation of customer relationship management

\section{Organizational Management of CRM / Management Steps of E- CRM}

Bradshaw and Brash suggested three essential points for organization to deal with customer relationship on internet

1. That building CRM in the front office is just the start, and that it must involves the back office functions like manufacturing, fulfillments and billing as well as the analytical functions like data warehousing and pushing customer insight back up to the front office.

2. That conducting relationship across multiple media requires the correct technical infrastructure, allowing companies to deal with their customers in a consistent way across multiple media and even add new media as required without the need to develop every interface separately and from scratch.

3. Building the correct strategy for directing customers to different media. For new organizations the strategy "we will deal with customers on whatever medium they prefer" is right; but for the vast majority of organization it is a recipe for disaster.

Bradshaw and Brash suggested a framework for customer relationship management called as virtuous triangle. This framework is for ideal CRM organization. The main aim of virtuous triangle is ensure that organization is fully aware about their customer needs. The virtuous triangle of CRM is consists of three elements that is back office, front office and analytic system which must be properly integrated to run CRM properly 


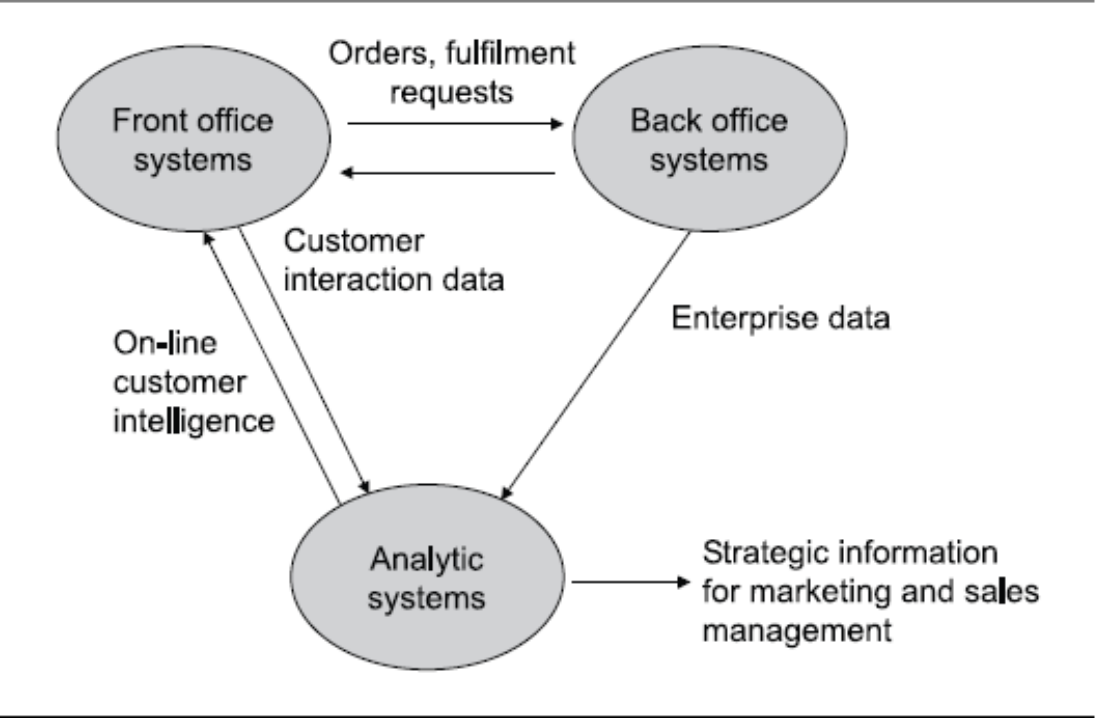

Figure .3: The "virtuous triangle" of CRM

\section{Conclusion}

The Conclusion of Literature Review with the analysis and discussions of different authors and their views, now leads to the development of Implementation Framework

\section{RESEARCH METHODOLOGY}

The section blankets the philosophy utilized by the scientist as a part of this examination. Choice of approach in the examination focused around the issues and exploration questions. Avocation and inspiration for system are expressed in this section.

\section{Introduction}

There are different approaches to do research. Fundamentally It might be compressed as per the measure of learning and experience an analyst holds in the field of study before beginning the exploration. By and large research might be characterized into three general classifications.
1. Explanatory
2. Descriptive
3. Exploratory

\section{Exploratory}

As indicated by Roution P (2007) exploratory examination is utilized when the exploration territory or issue is not well known. This exploration helps in deciding the examination outline and information gathering system.

Essentially exploratory exploration depends on auxiliary examination i.e. accessible writing and information. Auxiliary exploration will be talked about later in this section. The result of exploratory examination is for the most part not valuable for choice making however accommodating in giving 
knowledge into circumstance.

\section{Descriptive Research}

Stephen C. J expressed that spellbinding exploration is essentially the factual examination used to depict information. Generally, the answer of graphic examination inquiries are who, what, were, when and how. The goal here is to present a portrayal of different phenomena identified with individual occasions and circumstances.

\section{Explanatory Research}

As per Ruane J. logical examination is led when the issue and its portrayal are known and explanation behind the exploration is to know why these things are going on.

\section{Qualitative and Quantitative Research Approaches}

A Quantitative exploration methodology might be characterized as the request of known issues focused around testing and investigated with the assistance of factual procedures. Then again qualitative exploration is utilized to comprehend the human or social issues from diverse perspectives.

\begin{tabular}{|l|l|l|}
\hline & QUALITATIVE & QUANTITATIVE \\
\hline Objective & $\begin{array}{l}\text { To attain a qualitative understanding of the } \\
\text { fundamental reasons and motivations }\end{array}$ & $\begin{array}{l}\text { To accumulate the data and generalize the } \\
\text { outcome from the sample to the target population }\end{array}$ \\
\hline Sample & $\begin{array}{l}\text { Is based on a small number of non- } \\
\text { representative cases. }\end{array}$ & $\begin{array}{l}\text { Is based on a large number of representative } \\
\text { cases. }\end{array}$ \\
\hline $\begin{array}{l}\text { Data } \\
\text { Collection }\end{array}$ & Uses unstructured methods & Uses structured surveys \\
\hline $\begin{array}{l}\text { Data } \\
\text { Analysis }\end{array}$ & Non statistical & Statistical \\
\hline Outcome & Build a preliminary understanding & Propose a conclusive action plan \\
\hline
\end{tabular}

\section{Data Collection Method}

There are two ways to collect data for research purpose primary data collection and secondary data. This is discussed below:

\section{Primary Data}

In this sort of study, the analyst endeavors to accumulate all the information in reference to the territory of study. The purposes behind gathering information have different reason, for example, behavior research from a hierarchical insightful in which the specialist readies the surveys and does meetings to accumulate data. Essential examination is time exhausting as the analyst need to accumulate information from the gathering of individuals who are specifically or by implication in contact with the exploration subject. Essential examination is led when any applicable material can't be obtained from auxiliary exploration.

There are two sorts of perceptions in essential information: Participant and organized perception. Member perception's accentuation on qualitative while organized perception's stress on quantitative. 


\section{Collection of primary data}

Deliberate poll and interpersonal meeting are the most legitimate method for social affair information. It makes the information more practical and real. While directing gathering of essential information the scientist gathers new information i.e. not been aggregated in the recent past, be it from people or from a gathering of individuals.

\section{Collection and design of questionnaire}

In the gathering of information, planning of surveys assumes a basic part. Polls ought to be reasonable and short. The poll ought to unmistakably state your goals and how the information being referred to will be utilized. The inquiries ought to be compact and clear.

\section{Secondary Data}

In this sort of exploration, the scientist does not require straightforwardly to be by and by included. In this kind of exploration information is assembled from diverse sources, for example, electronic and printed adaptation of articles and/or detailed analyses of individual and associations.

\section{Resources of secondary data}

There are different wellsprings of data in auxiliary information research. The most widely recognized asset for gathering information could be magazines, daily papers, diaries, articles and inside authoritative archives.

\section{Data Collection Technique}

There are number of procedures through which data will be accumulated. The accompanying areas demonstrate the technique utilized via scientist to gather information.

\section{Document based}

While taking a shot at CRM in e-business and eCRM, the specialist discovered extremely helpful information amongst the exploration of creators who have helped gigantically around there of examination. One of the well-known paper based information accumulation asset the specialist utilized is "The Handbook of CRM" by Jil Dyche.

\section{Macro approach or digital searches}

Information gathering for this undertaking included different electronic assets, for example, Google researchers, Google books and progressed internet searchers (the web indexes), college scholastic site like find it and OPAC gives a stage to assembling scholarly data and pertinent information, journals and articles electronically likewise come in optional information.

\section{Accessibility of secondary data}

The most essential issue in auxiliary information is that it ought to be pertinent and be taken from a solid source and true. This is exceptionally paramount for analysts as information is real and dependable. 


\section{Advantages of secondary data}

The most paramount issue in optional information is that it ought to be significant and be taken from a solid source and legitimate. This is extremely vital for scientists as information is legitimate and solid.

\section{Disadvantages of secondary data}

While leading optional examination we may run over a few issues. The data gathered may be antiquated, conflicting or superfluous to the exploration regarding neglecting to fall inside the picked destination/inquiries of the examination. This is the reason this strategy is at some point improper as there may be understandings that are not precisely after the exploration goals.

\section{Reason for choosing secondary research}

CRM is one intriguing issue now days. A huge measure of exploration is, no doubt directed on CRM all through the world; this is a profit as writing and data accessible on CRM. That was the motivation to do research with optional information. With the assistance of distinctive overhauled articles and diaries scientists' gathers information for the examination which empowers the specialist to break down lastly show the suggestion focused around the gathered information. In correlation to essential exploration it is less time intensive and less furious.

\section{Resources used}

Secondary based research is based on the data which is available previously through difference sources; therefore, the researcher collects the relevant data of CRM from difference reliable sources such as:

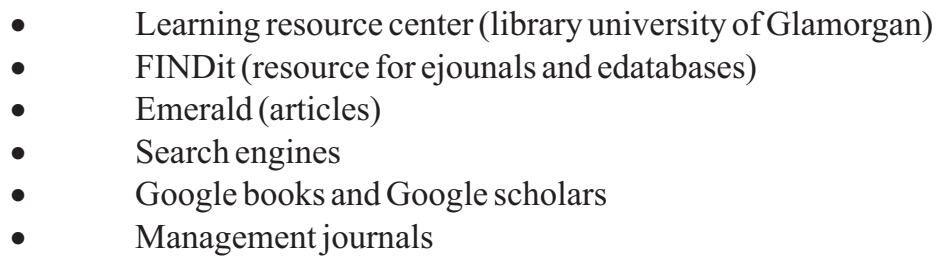

\section{Limitations}

This task helped the scientist to increase an incredible measure of exploration aptitudes and information about CRM which will be advantageous for the analyst while working in any association.

Despite the fact that the exploration brought about a sensible conclusion, there were a few components which influenced the execution of the analyst. Inaccessibility of complete examination papers or inaccessibility of books influence on the execution. As the CRM is hot issue now a day so a lot of data accessible making it difficult to utilize every last bit of it for this exploration.

\section{IMPLEMENTATION FRAMEWORK FOR CRM}

\section{Introduction}

The reason for this section is to give execution suggestions to skeleton of CRM to verify that the usage is on the right way and will be fruitful. To make it effective does incorporates the key advancements as well as considers determination of right engineering which assumes an imperative part alongside administration and backing. As beforehand it was said that assessment of CRM is an iterative 
procedure which incorporates the returning to of each steps through which the usage has experienced. In elaboration I have isolated them into two sections that is innovation administration and managerial level Management. Taking after are the focuses which I have separated into innovation level and managerial Level.

\section{Managerial Level Management}

- $\quad$ Define the Business Process

- $\quad$ Project Scoping

- $\quad$ Project Methodology

- $\quad$ Team Management (Required Skill Level)

- Business process functional

- $\quad$ Review and Analysis of business processes

\section{Technology Management}

- $\quad$ Technology Infrastructure

- $\quad$ Front End Technology

- Data Gathering

- Business Processes

- $\quad$ Back End Administration

- $\quad$ Maintenance Phase

After having the background and research all about the facts of CRM, I have list down the points which can be considered during or before the implementation of CRM which are as under:

\section{Managerial Level Recommendations}

- In order to understand the CRM implementation across all business units through which all the employees, suppliers, customers, partners bring together, it is important to develop a strategy to identify goals and objectives for CRM to be implemented.

- Information needed as pre requisite should be gathered and compiled.

- Organizations must standardized business processes that support the CRM in other words it's also called business process re-engineering.

- $\quad$ Perspective customers should be identified. So that the customers' loyalty can be increased.

- $\quad$ Technology selection should be proper to see its scalability

- $\quad$ CRM solutions need to be aligned with the business strategy

- $\quad$ Core Business areas should be integrated with to automate business processes

- $\quad$ Acquiring the basic reports for different level of organization users, such as specific monthly and weekly bases reports for management.

- $\quad$ Defining the appropriate administrative and personalization customization.

- $\quad$ A Team should be managed with the required skill sets and a hierarchy of reporting should be identified.

- Stack holders $\backslash$ Domain Specialist

- Project Managers

- Team Leads

O Software Engineers

O QATesters

- Level of Technological Concepts should be drawn to categorized the team members 


\begin{tabular}{|l|l|l|l|}
\hline Skill set & Low & Medium & Primary \\
\hline Technology Arch. & & & \\
\hline Programming & & & \\
\hline Database & & & \\
\hline Design & & & \\
\hline
\end{tabular}

- $\quad$ Project plan should be developed and reviewed to implementation of CRM

- Determining the risk factor and cost assessment.

- Defining the change management plan to make sure project do not go out of defined project time line and cost.

- $\quad$ At the time of scoping CRM projects these should be done:

- The technological understanding should be involved in the CRM implementation

- Learning the skills needed to implement CRM

number of staff members determine the that will be working on it

- Determine whether consultants will be used and if so what the number will be

- Establish a time frame

- $\quad$ A sound Development Roadmap should be set forth to ensure things go as per schedule.

- $\quad$ Training requirements should be identified for all the users

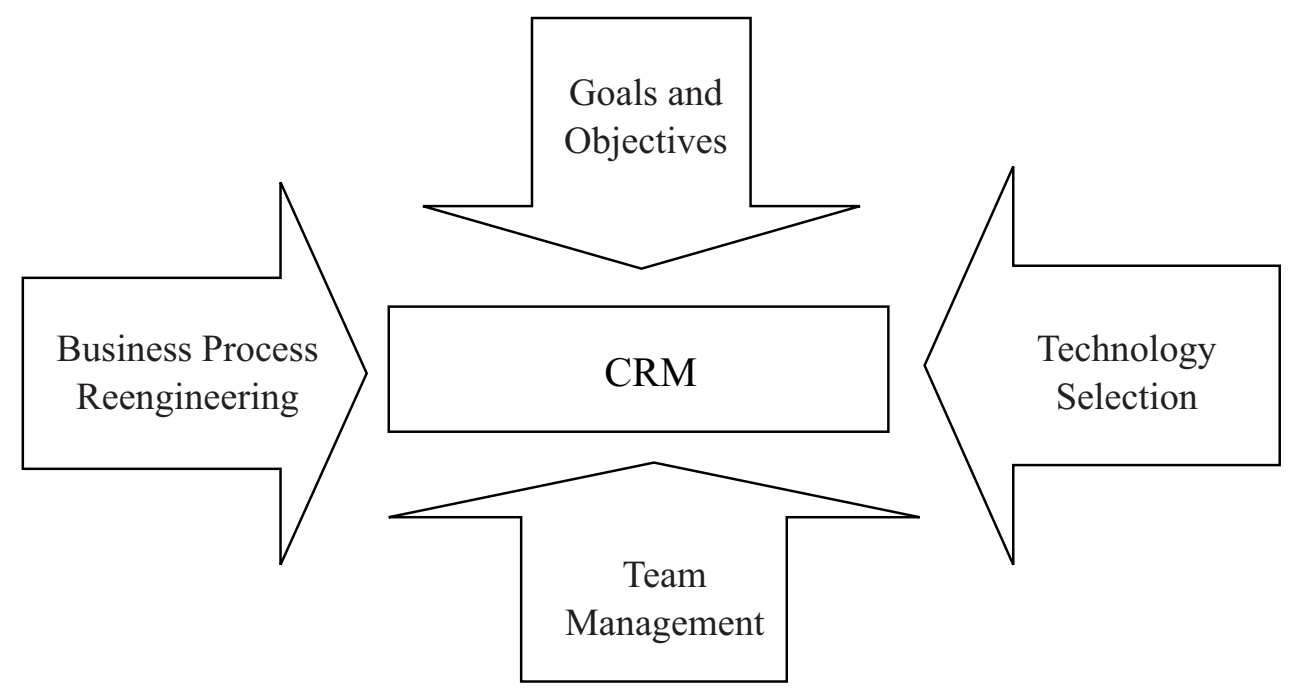

Figure .4: Diagrammatic Presentation of CRM at Initial Phase

\section{Technical Level Recommendations}

- Understanding of existing system and infrastructure, and providing purposed infrastructure solution as prerequisite of CRM implementation.

- Determining intranet and extranet, online and offline requirements.

- There should be proper information for a CRM solution only after appropriate information has been sought and analyzed.

- CRM implementation will essentially involve functional staff which means that care should 
be taken to assign the roles of the project team and functional staff in a manner that is not inappropriate

- There should not be a hard core configuration application for CRM instead a customization which requires Business processes to be incorporated

- There should be Multi-tiered application to get more accessibility.

- It is also recommended to ensure that CRM development is executed around a structured development business process.

- Defining the template management and customization of search engine.

- Technically the entire CRM system Architecture should be categorized in to the following parts:

$\begin{array}{ll}\circ & \text { Front End Technology } \\ \circ & \text { Back end Technology } \\ \circ & \text { Business processes } \\ \circ & \text { Maintenance }\end{array}$

- Understanding with the current trends for front end technology should be adopted.

- Concepts of minimum navigation should be followed to avoid information digging kid of stuff.

- As the front end provides the Customer to access different departments to be communicated, that should be streamlined and available just on few clicks.

- There should be an information update mechanism with minimum efforts to let the users know all about the new stuffs or services.

- As each interaction of customer provides an organization a transaction, that should be properly maintained

- Back end technology provides a way to store data for each transaction between customer and organization, the Back end database along with the services should be capable of handling users request within no time and scalable to next four to five years.

- The back end database should be capable of providing data warehousing and data mining capabilities

- The back end database architecture should be designed $\mathrm{n}$ such a manner that it provides a minimum down time.

- The back end technology also consists of hardware upon which the CRM system is running should capable of handling many requests

- While developing the requirements for CRM systems, a disaster recovery plan should be developed.

- At the end of project execution, the maintenance plan should be developed and provides those users a short training. 


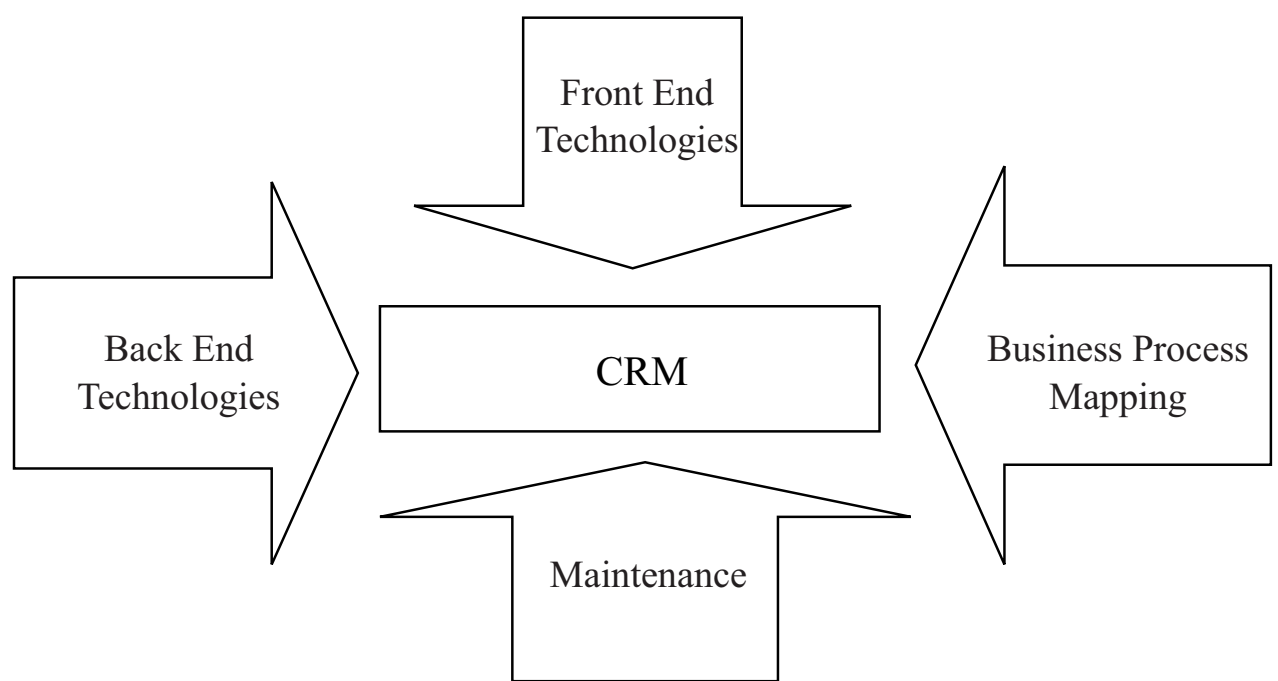

Figure.5: Diagrammatic Presentation of CRM at Second Phase

\section{CONCLUSIONAND RECOMMENDATIONS}

In today's focused world, CRM has turned into a standard necessity. Regardless of the measure of the association, regardless of if the client is a wholesaler or the end client. CRM has ended up crucial for development and must be looked upon as a financing as opposed to a load.

According to exchange and assessment of the system, this section will give a correlation between the recommended skeleton and the assessments of the structure. The fundamental object is to highlight those parts which are specified by industry guidelines.

\section{Conclusion}

Basically the proposed framework in my thesis provides a panoramic view, which covers all the smaller bits and pieces of the implementation activities. As we review the framework component which are mentioned in previous chapter are:

- Technology Infrastructure

- $\quad$ Front End Technology

- $\quad$ Data Gathering

- Business Processes

- $\quad$ Back End Administration

- Maintenance Phase

In a closer look and deep study of these components will elaborate so many things that can be hard to cover in this thesis. Whereas those points that are added in the evaluation of the framework are mostly cover in the above mentioned components. To facilitate those points along with their reasons are shown below 


\section{Evaluators Points}

\section{User Authorization and Privileges}

This part is not specified particularly in the segments of structure, whereas this returns under end Administration, if characterized all the more in profound it could be explained here, which is when choosing the Technology Infra structure it is one of the imperative congratulatory gesture when characterizing the Roles and their obligation objects. Further a progression ought to must be created with Rights and Responsibilities. Once the action will be carried out catch up will be application level undertaking could be characterize effortlessly. Though this User administration Results could be contrasted and the current practices as diverse client will be performing their own particular undertaking and obligations inside their territory of ability. Going to Implement Security there a study requires to full fill the needs of the client to get to the framework, which could be recorded as under:

$\begin{array}{ll}\checkmark & \text { Security Requirements } \\ \checkmark & \text { Security Levels } \\ \checkmark & \text { Access Control } \\ \checkmark & \text { Users, Roles and Authorizations } \\ \checkmark & \text { Technical Implementation of Roles }\end{array}$

A List of Certain Users can be categorized as under:

\begin{tabular}{|l|l|l|}
\hline Sr.\# & User type & Description of Rights \\
\hline 1. & Administrator & Highest Rights of User \\
\hline 2. & Manager & Management Level Reporting Rights \\
\hline 3. & Process Administration & Specific to Processes involved \\
\hline 4. & Data Entry Operators & An ordinary user with minimum access \\
\hline
\end{tabular}

Some General Tasks upon which the analysis is required are as under:

$\begin{array}{ll}\checkmark & \text { Create, maintain, lock and unlock users, and change passwords } \\ \checkmark & \text { Create and Maintain Roles } \\ \checkmark & \text { Maintain Transaction and Authorization Data in Roles } \\ \checkmark & \text { Generate Authorization Profiles } \\ \checkmark & \text { Assign Roles and Profiles } \\ & \text { Monitor Using the Information System, Archive Documents etc }\end{array}$

A typical scenario is needed to be designed for the purpose of Authorization Implementation Example of such scenarios is as under.

\section{Scenario 1}

$\checkmark \quad$ Central user administration

- One user administrator for all users

- Unlimited authorizations for all user administration tasks of the user administrator

$\checkmark \quad$ Central maintenance of roles and profiles

- One administrator takes on both roles

- Authorization data administrator

- Authorization profile administrator

$\circ \quad$ All authorizations for maintaining the roles and profiles

$\checkmark \quad$ Principle of dual control

\section{$\checkmark \quad$ Scenario 2}

$\checkmark \quad$ De-central user administration (production system)

- One user administrator per application area (Finance, Production etc) 
- Authorized to maintain a certain user group

- $\quad$ Authorized to assign a certain number of roles and profiles

- $\quad$ No other restrictions in the specific user administration tasks

$\checkmark \quad$ Central maintenance of roles and profiles

$\circ \quad$ Separation of responsibilities

- One authorization data administrator

- One authorization profile administrator

- No other restrictions in the specific roles or profiles for both administrators

$\checkmark \quad$ Principle of triple control

\section{Sizing Terminology}

Measuring Terminology is a critical and discriminating part, which ought to be a piece of engineering foundation and ought to be characterized legitimately to expand the first piece of usage skeleton. This is an essential viewpoint and ought to be added to give the proposed system a best practice. Fundamentally the measuring wording according to assessment proposes that the estimating assumes an extremely paramount part in the whole life cycle of client relationship administration, to the extent that the hard product execution is perfect with the CRM application, the more extended will be the length of time of CRM framework. In most ERP applications estimating is the part after the venture acknowledgment began and fittings proposals is constantly gathered from the specialized usage group of CRM, which then investigation the prerequisites either focused around clients or focused around number of transactions performed inside or outside the association. While the client based measuring of the fittings equivalently simple and speedy to characterize the equipment measure that incorporate number servers if the framework is appropriated, typically there will be a three level scene, composed and used for better organization and exhibitions. After this whatever is left of stages will happen till it's GO Live.

\section{Business process}

Business procedure is likewise one of the key regions in the execution of CRM system where an intensive study obliges redoing the business methodology is now specified in the segment of edge work.

\section{Maintenance Phase}

There are more things are required to specified according to evaluator, this ought to be explained in point of interest as there are different phrasings utilized like Solution Contract/ Service License Agreement. This ought to be said painstakingly as there are different realities needs to be cleared before actualizing the Solution of CRM.

\section{Front End Technology}

According to the announcement of evaluator the front end innovation obliges more noteworthy aptitudes and needs past encounters in utilizing the front end engineering. As this will help in giving better application building design. As indicated by the assessment and proposals in fact the truth of the matter is front end innovation generally encourage those clients or client who will associate after its executions. Generally, the wording utilized as GUI (Graphical User Interface).

Amid this extend the targets were marginally reshaped. On accepting counsel from the venture director with respect to stage dependent skeleton, the structure was made blander instead of based around one or a handful of programming. This made the system adaptable and equipped to be 
executed with any product.

\section{REFERENCES}

Archer, N.; Yuan, Y. (2017). Managing business-to-business relationships throughout the ecommerce procurement life cycle. Internet Research, Vol. 10, No. 5, pp385-395.

Bayon T, Gutsche J \& Bauer H. (2015). Customer Equity Marketing: Touching the intangible. European management Journal. 20 (3), 213-222.

Berson, A.; Smith, S.; Thearling, K. (2016). Building data mining applications for CRM. McGrawHill, USA.

Bradshaw D \& Brash C.. (2007). Managing customer relationship in the e-business world how to personlise computer relationships for increased profitability. International journal of retail and distribution . 29 (12), 520-529.

Brobst, S. (2007). Data Warehousing from the Trenches: Your Business Strategy is Only as Good as Its Execution. DM Review, March 2002, DMReview.com.

Chang, J. (2009). CRM Suites for Medium to Large Enterprises. The Customer Relationship Management Solutions Guide, 3rd Edition, August 2001, CRMguru.com .

Chang, J. (2005). A Guide to Evaluating CRM Software. The Customer Relationship Management Solutions Guide, April 2002, CRMguru.com.

Close, W. (2009). The Need for a Multi-Vendor Strategy in Achieving Outstanding CRM. Defying the Limits, Vol. 2, CRMproject.com, Montgomery Research, Inc

Chaston I. (2010), e-marketing strategy, England McGraw Hill

Dyche J (2001). The CRM Handbook. London: Addison-Welson

Day, G. S. (2000) Managing Market Relationships. Journal of the Academy of Marketing Sciences, Vol. 28, No. 1, pp 24-30.

Feinberg, R. A.; Trotter, M. (2001). Immaculate Deception: The Unintended Negative Effects of the CRM Revolution. Defying the Limits, Vol. 2, CRMproject.com

Hwang, H.; Yeh, R.; Chen, H.; Jiang, J. J.; Klein, G. (2002). IT Investment Strategy And IT Infrastructure Services. The Review of Business Information Systems, Vol. 6, No. 2

Jefferies C. S. (1999). Descriptive Research. Available: http://www.cwu.edu/ jefferis/PEHL557/pehl557_descript.html. Last accessed 10 spet 08.

Kim J, Suh E \& Hwang H. (2003). A model for evaluating the effectiveness of CRM using balanced scorecard. Journal of interactive marketing. 17 (2), 5-19.

Kellen V. (2002). CRM Measurement Frameworks. kellen.net.

Korner, V.; Zimmermann, H. (2000). Management of Customer Relationship In Business Media The Case of the Financial Industry.

Neill J. (2006). Qualitative Research. Available: http://wilderdom.com/OEcourses/PROFLIT/Class6Qualitative1.htm\#Types. Last accessed 10 spet 2008 .

Petrissans, A. (1999). Customer Relationship Management: The changing economics of customer relationship white paper.

Rud, O. P. (2011). Data Mining Cookbook. John Wiley \& Sons, Inc., NY, USA.

Renner, D. (2011). Closer to the Customer: Customer Relationship Management and the Supply Chain. Montgomery Research Inc., Ascent Volume1

Ryals L \& knox S. (2012). Cross funcational issues in the relational implementation of relationship marketing through customer relationship management. European Management Journal. 19 (5), 534-542.

Routio P. (2007). Models in the Research Process. Available: http://www2.uiah.fi/projects/metodi/177.htm\#explor. Last accessed 10 Sept -08.

Ruane M J (2004). Essentials of Research Methods. London: Blackwell Publishing.

Sterne J (2000). Customer Service on the internet. 2nd ed. United States of America: Wiley computer publishing. 
IBT Journal of Business Studies

Schroeck, M. (2001). Customer Analytics Making the Difference in CRM: Customer Analytics Amplify the Value of Integrated CRM Solutions. DM Review, September 2001, DMReview.com

Schroeck, M. (2001). Customer Analytics Making the Difference in CRM: Customer Analytics Amplify the Value of Integrated CRM Solutions. DMReview.com

Unr.(n.d). Quantitative and Qualitative Research. Available: http://www.unr.edu/bench/chap04.pdf. Last accessed 11 spet 2008.

Wilson H, Daniel E \& McDonal M. (2002). Factor for success in CRM system. Journal of marketing management. 18(1), 193-219. 